This is an electronic reprint of the original article. This reprint may differ from the original in pagination and typographic detail.

\author{
Author(s): Viljaranta, Jaana; Silinskas, Gintautas; Lerkkanen, Marja-Kristiina; Hirvonen, Riikka; \\ Pakarinen, Eija; Poikkeus, Anna-Maija; Nurmi, Jari-Erik
}

Title: Maternal homework assistance and children's task-persistent behavior in elementary school

Year: $\quad 2018$

Version:

Please cite the original version:

Viljaranta, J., Silinskas, G., Lerkkanen, M.-K., Hirvonen, R., Pakarinen, E., Poikkeus, A.M., \& Nurmi, J.-E. (2018). Maternal homework assistance and children's taskpersistent behavior in elementary school. Learning and Instruction, 56, 54-63. https://doi.org/10.1016/j.learninstruc.2018.04.005

All material supplied via JYX is protected by copyright and other intellectual property rights, and duplication or sale of all or part of any of the repository collections is not permitted, except that material may be duplicated by you for your research use or educational purposes in electronic or print form. You must obtain permission for any other use. Electronic or print copies may not be offered, whether for sale or otherwise to anyone who is not an authorised user. 
NOTICE: This is the author's version of a work that was accepted for publication in Learning and Instruction. Changes resulting from the publishing process, such as peer review, editing, corrections, structural formatting, and other quality control mechanisms may not be reflected in this document. Changes may have been made to this work since it was submitted for publication. A definitive version was subsequently published in Learning and Instruction, 56, 54-63. doi:10.1016/j.learninstruc.2018.04.005 
Running head: HOMEWORK ASSISTANCE AND TASK-AVOIDANT BEHAVIOR

Maternal Homework Assistance and Children’s Task-Persistent Behavior in Elementary School

Jaana Viljaranta $_{\mathrm{a}}$, Gintautas Silinskas, , Marja-Kristiina Lerkkanen, Riikka Hirvonen $_{b}$, Eija Pakarinen $_{c}$, Anna-Maija Poikkeus, , and Jari-Erik Nurmi ${ }_{b * *}$

a University of Eastern Finland, Philosophical Faculty, School of Educational Sciences and Psychology, P.O. Box 111, 80101 Joensuu, Finland b University of Jyvaskylä, Department of Psychology, P.O. Box 35, FI-40014 University of Jyvaskylä, Finland

c University of Jyvaskylä, Department of Teacher Education, P.O. Box 35, FI-40014 University of Jyväskylä, Finland

${ }^{1}$ Author for correspondence: Jaana Viljaranta, University of Eastern Finland, Philosophical Faculty, School of Educational Sciences and Psychology, P.O. Box 111, 80101 Joensuu, Finland. email: jaana.viljaranta@uef.fi

** In memoriam. Jari-Erik Nurmi has passed away. 
- Mother's homework assistance was related to child's task persistence

- Autonomy granting was related to exhibiting higher levels of task persistence

- Help was related to exhibiting less task-persistent behaviour

- Child's task persistence contributed on mothers' homework assistance

- The results indicate that not all assistance leads to positive outcomes. 


\begin{abstract}
The present study used a sample of 365 children to investigate the longitudinal associations between maternal homework assistance (i.e., help, monitoring, and autonomy granting) and children's task-persistent behavior in learning situations from grade 2 to grade 4 of elementary school. Also, the extent to which task-persistent behavior plays a role in the links between parental homework assistance and children's academic performance was examined. The results showed that the more autonomy granting mothers reported, the more taskpersistent behavior children exhibited; and more task-persistent behavior children exhibited, the more autonomy their mothers granted. In contrast, the more mothers helped their children, the less task-persistent behavior was reported, and the less task-persistent behavior children exhibited, the more mothers tried to help and monitor their children later on. Additionally, some evidence was found supporting the role of task-persistent behavior in the relation between maternal homework assistance and academic performance.
\end{abstract}

Keywords: help, monitoring, autonomy granting, task-persistent behavior, performance 


\section{Maternal Homework Assistance and Children's Task-Persistent Behavior in Elementary School}

Parents are involved in their children's schooling in several ways. One of the most typical forms of such involvement is assistance with homework (Jeynes, 2005; Patall, Cooper, \& Robinson, 2008; Pezdek, Berry, \& Renno, 2002; Pomerantz \& Eaton, 2001), which is assumed to have a positive effect on different schooling outcomes, not only on academic achievement (for a review, see Patall et al., 2008) but also motivation-related behavior (e.g., Leone \& Richards, 1989; Shumow, 1998). Interestingly, previous literature has mainly focused on direct links between parental homework practices and children's skill development and found rather contradictory results concerning the benefits of parental homework assistance: some studies have found a positive association between parental homework assistance and children academic performance (Dumont et al., 2012; Patall et al., 2008), whereas in some studies a negative effect has been found (Cooper, Lindsay, \& Nye, 2000; Hill \& Tyson, 2009; Silinskas, Niemi, Lerkkanen, \& Nurmi, 2013). It has, further, been acknowledged that different types of homework practices are differently associated with children's schooling outcomes (e.g., Silinskas, Kiuru, Aunola, Lerkkanen, \& Nurmi, 2015; see also Patall et al., 2008), which partly explains the contradictory findings.

However, one important limitation in previous research is that it has often neglected the role of motivation-related behavior, such as task persistence, in relation to homework assistance and school achievement. This is surprising, because it has been suggested that motivation-related factors may help to explain the previous contradictory findings regarding the relations between homework assistance and children's skill development (see Patall et al., 2008). Only a few studies have examined the associations between the different types of parental assistance and children's motivation-related factors longitudinally (for exceptions, see Dumont et al., 2012; Dumont, Trautwein, Nagy, \& 
Nagengast, 2014), and also taken the role of skills into account simultaneously. The present study aims to fill these gaps in previous literature by examining the longitudinal relations between different types of maternal homework assistance (help, monitoring and autonomy granting) and the behavioral aspect of children's motivation, that is, task persistence, from Grade 2 to Grade 4 of elementary school, after controlling for children's skill level. Additionally, the study aims to examine whether there are indirect effects between maternal homework assistance and children's skills via task-persistent behavior.

\subsection{Homework Assistance}

Previous literature often defines parental homework involvement either in terms of the amount or frequency of such involvement or in terms of the quality of involvement (Moroni, Dumont, Trautwein, Niggli, \& Baeriswyl, 2015; Silinskas \& Kikas, 2017; Xu, Fan, $\mathrm{Du}, \& \mathrm{He}, 2017)$. Also, it typically distinguishes between different types of homework involvement (e.g., Pomerantz, Moorman, \& Litwack, 2007; Grolnick \& Ryan, 1989; Grolnick, 2003; Dumont et al., 2012, 2014; Ng, Kenney-Benson, \& Pomerantz, 2004; Hoover-Dempsey \& Sandler, 1997). In the present study, the focus is on the amount of three different types of homework assistance.

Recent literature on parental homework assistance has often relied on the ideas of Ryan and Deci's (2000) self-determination theory (SDT) as a theoretical framework to distinguish the different types of assistance (for a review, see Pomerantz et al., 2007; see also Pomerantz \& Eaton, 2001; Silinskas et al., 2013; 2015). According to SDT, feelings of competence and autonomy (as well as relatedness) are essential for all motivated behavior (Ryan \& Deci, 2000; Deci \& Ryan, 2008), and different kinds of parental practices satisfy children's needs for competence and autonomy in different ways. First, autonomy support is defined as allowing children's independence and own initiative in solving various problems and challenges (Deci \& Ryan, 2008; Deci, Vallerand, Pelletier, \& Ryan, 1991; Pomerantz et 
al., 2007; Ryan \& Deci, 2000). In homework assistance situations, this means that if autonomy is granted, a parent trusts that the child will be able to work independently and take responsibility for his or her own homework (Silinskas et al., 2015, see also Pomerantz et al., 2007). This, then, will lead to an increase in children's feelings of autonomy and competence.

In contrast, more controlling parental behavior involves regulating children's actions through different kinds of methods, such as commands or directives. In previous literature on homework assistance, this more controlling type of parental assistance has typically been further divided into help and monitoring (Pomerantz \& Eaton, 2001; Pomerantz et al., 2007; Silinskas et al., 2013, 2015). Help can be conceptualized as active teaching and guiding a child in his or her homework, whereas monitoring refers to checking whether children's homework is complete and correct. Pomerantz and Eaton (2001) have suggested help and monitoring to present forms of intrusive support in situations where a parent may help and monitor child's homework even when the child does not ask for it, which could lead to diminished feelings of autonomy and competence. However, Silinskas and colleagues $(2013,2015)$ have conceptualized help and monitoring not in terms of their intrusiveness but rather based on how directly parents are involved in their children's homework. In the case of help, the level of direct involvement is high, in terms of the parent actively and directly helping the child with homework tasks by, for example, sitting next to the child and working on the task together. In the case of monitoring, in turn, the level of direct involvement is lower in terms of the parent making sure the child has done his / her homework by, for example, asking if the tasks are completed. Both help and monitoring, despite the different level of direct involvement, may diminish children's competence beliefs and feelings of being able to autonomously take care of their schooling. The present study will focus on all three dimensions of maternal homework assistance: autonomy granting, 
help, and monitoring following the conceptualization by Silinskas et al. $(2013 ; 2015)$ where help and monitoring are distinguished based on the level of direct involvement.

The majority of previous literature has focused on the effect of homework assistance on children's skill development. However, the findings in the field are contradictory. Some of the findings have shown that both parental help (Cooper et al., 2000; Hill \& Tyson, 2009; Silinskas et al., 2013) and monitoring (Patall et al., 2008; Silinskas et al., 2013) are negatively related to children's academic performance. Some other studies have found a positive association between parental homework assistance and children academic performance. For instance, Pomerantz and Eaton (2001) found that mothers' help and monitoring were related to the improvement of performance over time. Moreover, in their meta-analysis, Patall et al. (2008) found a small but significant positive correlation between parental help in homework and students' academic achievement. Studies examining the role of autonomy granting have shown that granting autonomy in homework situations positively contributes to children's academic performance (Cooper et al., 2000; Ng et al., 2004).

One reason for these contradictory results may be related to the differences in how homework assistance is measured (e.g., frequency or quality; Moroni et al., 2015). Another reason, however, concerns factors that may contribute to the relations between homework assistance and children's academic achievement and skill development (see Patall et al., 2008). An example of these kinds of factors is children's motivation-related behavior, such as task persistence.

\subsection{Homework Assistance and Children's Task-Persistent Behavior}

The important aspect of students' learning motivation is the way in which students behave when they face different kinds of learning tasks. The term "task-persistent behavior" refers to adaptive, on-task behavior in response to challenging academic tasks (e.g., Onatsu-Arvilommi \& Nurmi, 2000). Children who show high task persistence put effort in 
and concentrate on tasks at hand, and they do not easily give up even when they face challenging tasks and difficulties (Aunola, Nurmi, Niemi, Lerkkanen, \& Rasku-Puttonen, 2002; Onatsu-Arvilommi \& Nurmi, 2000). Task persistence is related to learning goals (Onatsu-Arvilommi \& Nurmi, 2000) and it has repeatedly been found to be positively associated with academic skill development: Children who are persistent even in the face of challenges have better skills later on (e.g., Aunola, Nurmi, Lerkkanen, \& Rasku-Puttonen, 2003; Hirvonen, Georgiou, Lerkkanen, Aunola, \& Nurmi, 2010; Onatsu-Arvilommi \& Nurmi, 2000). The relationship between skill development and task-persistent behavior has actually been suggested to be reciprocal so that better skills also contribute to later task persistence (e.g., Aunola et al., 2002; Hirvonen et al., 2010). It is possible that when children have good skills, they also believe in their abilities which, then, helps them to be persistent in challenging tasks (e.g., Eccles et al., 1983; Eccles, 2005). Although previous literature has suggested that parental homework assistance is associated not only with children's skill development but also with their motivation-related behavior (Dumont et al., 2012; 2014; Leone \& Richards, 1989; Shumow, 1998), studies examining the relations between homework assistance and children's task-persistent behavior are rare (for exceptions, see Dumont et al., 2014; Kikas \& Silinskas, 2016; Silinskas \& Kikas, 2017).

As stated earlier, according to the SDT, feelings of competence and autonomy are essential for motivated behavior (Ryan \& Deci, 2000; Deci \& Ryan, 2008; see also Aunola, Viljaranta, Lehtinen, \& Nurmi, 2013; Deci et al., 1991). This framework has also been used to explain why different kinds of parental homework assistance practices affect children's skill development (Silinskas et al., 2013; 2015) and are also related to children's task-persistent behavior (Kikas \& Silinskas 2016; Silinskas \& Kikas, 2017). Autonomy granting can increase children's motivation and effort in learning tasks (Deci \& Ryan, 2008; Deci et al., 1991; Ryan \& Deci, 2000), because children's need for autonomy and 
competence are fulfilled when parents show trust in children's ability and willingness to take care of their homework autonomously. In general, autonomy-supportive parenting has been found to contribute to children's psychological need satisfaction (Soenens et al., 2007; Van der Kaap-Deeder, Vansteenkiste, Soenens, \& Mabbe, 2015; Van Petegem et al., 2017). Previous research has, indeed, shown that allowing children to solve problems by themselves enhances their intrinsic motivation, sense of autonomy and competence, and also their persistent behavior (Deci, Schwartz, Sheinman, \& Ryan, 1981; Moorman \& Pomerantz, 2008). In comparison to autonomy granting, help and monitoring can be seen as more controlling types of practices that may lead to a decreased sense of autonomy and competence in the learning process (Pomerantz et al., 2007), and, thus to lower motivation and less effort. It has also been suggested that more controlling homework practices lead the child to think negatively about his or her performance, which in turn decreases child's effort in school tasks (Pomerantz \& Eaton, 2001; Pometantz et al., 2007; Silinskas et al., 2013).

As far as we know, there are only few previous studies focusing, first, on the relations between parental homework assistance and children's task persistence and, second, on the role that task persistence may play in the relationship between homework assistance and children's academic performance. Kikas and Silinskas (2016) examined the relations between maternal help (but not other types of assistance, that is, monitoring and autonomy granting), task-persistence, and reading performance in Estonia in the first two grades of elementary school. They found that the level of children's reading skills predicted children's task persistence in later learning situations which, then, contributed to mothers' behavior in homework situations. However, the study did not find evidence of the opposite direction of relations: Maternal help did not have an impact on children's later task persistence, and no evidence was found for the impact of maternal help on children's reading performance via children's task persistence. In a more recent study, Silinskas and Kikas (2017) 
conceptualized homework assistance in terms of its quality, that is, control versus support, and found that parental control in math-related homework was related to children's lower math performance and lower task persistence in grade 6. Parental support, in turn, was related to higher task persistence. In that particular study, however, Silinskas and Kikas included child-reports of parental support and control only from one time point (6th grade), and they did not find evidence that the effect of these two types of parental homework assistance on children's subsequent performance would be mediated by children's task persistence. Finally, Dumont et al. (2014) have conceptualized homework assistance in terms of parental control, parental responsiveness, and parental structure to examine how parental homework assistance is related to children's academic functioning (e.g., effort). In their study, the authors found that parental structure in grade 5 predicted students' reading effort in grade 7 . In the present study, we aim to broaden the understanding of the longitudinal relations between homework assistance and children's motivation-related behavior by examining, first, how different types of homework assistance and children's task-persistent behavior are longitudinally related across grades 2, 3 and 4, and, second, to what extent task persistence contributes to the relationship between homework assistance and children's skill development in math and reading.

\subsection{Evocative Effect of Children's Characteristics on Parents' Homework}

\section{Assistance}

Although it is widely assumed that parents' behavior promotes children's school-related outcomes, such as academic performance and motivation, it has been also suggested that the opposite direction can be true: Parents may adjust their homework assistance according to children's motivational and behavioral characteristics, and academic performance (e.g., Dumont et al., 2014; Silinskas \& Kikas, 2017; Nurmi, 2012). This kind of "evocative effect," as Scarr and McCartney (1983) termed it, refers to the extent to which the 
characteristics of the child (e.g., their academic performance and motivation), influence the behavior of their significant others. It can be assumed that parents, for example, can observe by themselves and/or be told by the teachers that their child exhibits poor performance and a low level of motivation. This can motivate parents to get involved more directly with their children during homework situations by helping and monitoring more. Alternatively, if a child remains persistent when facing difficult tasks, his or her parent may naturally provide more autonomy and trust him or her in completing homework. However, even though it is plausible to expect that parents take their children's task-persistent or task-avoidant behavior into account when engaging in homework assistance, this possibility has rarely been examined in homework assistance literature (Dumont et al., 2014). This may be due to the fact that longitudinal studies on this topic are still rare (as an exception, Kikas and Silinskas [2016] found that children's lower task persistence predicted more frequent academic help from mothers later on). The present study aims to fill in the gap in previous literature by examining longitudinally whether children's task-persistent behavior later predicts maternal help, monitoring or autonomy granting over three time points from grade 2 to grade 4 .

\subsection{Aims}

The aim of the present study was first to examine the cross-lagged relations between the different types of maternal homework assistance and children's task-persistent behavior from Grade 2 to Grade 4, and, second, to investigate what role task persistence plays in the relationship between maternal homework assistance and children's academic performance in math and reading.

The following research questions were investigated:

1. To what extent does mothers' homework assistance (help, monitoring, and autonomy granting) in homework situations predict children's task-persistent behavior across grade 2 to grade 4 of elementary school, controlling for children's academic performance? It 
was hypothesized (Hypothesis 1) that different types of maternal homework assistance contribute differently to children's task persistence. Based on the SDT theory (Deci \& Ryan, 2008; Deci et al., 1991; Ryan \& Deci, 2000), it was expected that higher levels of maternal autonomy granting predict higher levels of children's task persistence, because allowing children to solve problems by themselves enhances their sense of autonomy and competence, and their persistent behavior (Deci et al., 1981; Moorman \& Pomerantz, 2008). Maternal help, in turn, was expected to negatively predict children's later task persistence, because help represents a high level of mothers' direct involvement in homework situations and can, therefore, be seen as a more controlling action (especially when given without child's need for help). This may, then, lead to a decreased sense of autonomy and competence in the learning process (Pomerantz et al., 2007), and to lower persistence in learning tasks. Finally, monitoring, as it refers to somewhat controlling but less direct maternal involvement in homework situations in terms of checking whether homework is complete and correct, was assumed to play a small negative role in children's task persistence.

2. To what extent does children's task-persistent behavior predict mothers' homework assistance (help, monitoring, and autonomy granting) in homework situations across grade 2 to grade 4 of elementary school, controlling for children's academic performance? Previous findings on homework assistance and academic performance, especially, have shown that children's characteristics have an evocative effect on their parents' reactions toward them (e.g., Dumont et al., 2014; Pomerantz \& Eaton, 2001; Silinskas et al., 2013; for task persistence and maternal help, see Kikas \& Silinskas, 2016; for task persistence and self-concept and maternal control, see Silinskas \& Kikas, 2017). Therefore, it was hypothesized (Hypothesis 2) that mothers adjust their homework assistance according to children's task-persistent behavior: Higher levels of task persistence will lead to 
a higher level of autonomy granting, whereas lower levels of task-persistent behavior lead mothers to help and monitor their children's homework more.

3. Does children's task-persistent behavior play a role in the relation between mothers' homework assistance and children's academic performance? Due to a lack of previous longitudinal studies on this topic, no exact hypotheses were set concerning the indirect effects of different homework practices on skill development via task persistence, or vice versa. However, based on the study by Kikas and Silinskas (2016), it was considered plausible that there would be an indirect effect, especially from children's skill level to maternal practices via children's task persistence.

\section{Method}

\subsection{Participants and Procedure}

The data presented here is a part of an ongoing longitudinal study (AUTHORS REMOVED) that aims to investigate children's development during kindergarten and elementary school in family and school contexts. This particular study analyzed data regarding 365 parent-teacher-child triads obtained at three time points: the end of Grade 2 (T1; April), the end of Grade 3 (T2; April), and the end of Grade 4 (T3; April) of elementary school. At each time point, similar kinds of data were gathered. Children's reading and math skills were examined with group tests performed by trained research assistants. Teachers evaluated children's task-persistent behavior via questionnaires, and the children's mothers were asked to fill in questionnaires concerning their homework assistance.

Children. In total, 365 target children (176 girls, 189 boys) were sampled randomly from a larger sample of approximately 2000 children (at the end of kindergarten) in order to decrease teachers' work load and allow this subsample to be followed in a more detailed way than the whole sample. Due to variations in classroom size, the number of 
children included from different classrooms ranged between 1 and 6 , with a median of 3 . A total of 126 teachers rated students' task persistence in Grade 2; thus 365 students were rated by their teachers. In Grade 3, 362 children were rated by 120 teachers; and in Grade 4, 346 children were rated by 111 teachers. When the sample of students was compared to the children whose teachers did not participate in Grade 2, no significant differences were found between the groups in terms of children's gender, age, reading and math skills, or parents' education.

Only children whose parents gave written consent to participate were tested. The sample was highly homogeneous in terms of ethnic and cultural background, which is typical of a school population outside of metropolitan region of Finland. The children's family backgrounds were representative of the general Finnish population (Statistics Finland, 2010).

Teachers. Teachers were asked for their written consent to participate. In Grade $2,45 \%$ of the teachers had more than 15 years of teaching experience, $36 \%$ had $6-15$ years of experience, $15 \%$ from 1-5 years of experience, and $4 \%$ had less than one year of experience (Mode $=$ more than 15 years). About $80 \%$ of the teachers had at least a master's degree in education, and the remaining $20 \%$ had a bachelor's degree in education, both including classroom teacher qualification.

Mothers. Completed questionnaires were received from 289, 276, and 246 mothers in Grades 2, 3, and 4, respectively. Drop-out analyses identified no instances in which the reading or math performance of children whose mothers' reports were available would be different from the reading and math performance of the children whose mothers' reports were missing.

\subsection{Measures}


The psychometric properties of the mother-, teacher-, and child-related variables are presented in Table 1.

\subsubsection{Mothers' Questionnaire}

Mothers were sent questionnaires concerning their homework assistance in grade 2 , grade 3 , and grade 4 . Identical 10 items were used at all time points. Reliability and validity information for the measure has been previously published by Silinskas et al. (2015). Three distinct factors - help, monitoring, and autonomy granting - were extracted with the 10 items each loading only on the theoretically meaningful factor (see Silinskas et al., 2015, for detailed information). When re-analysing the measure for the present study, a factor analysis with principal axis factoring identified the same 3 distinct factors with eigenvalues over 1 at all 3 measurement points.

Help. Mothers' help with their children's homework was measured using four items (e.g., Do you help or guide your child in his/her homework?). Answers were given on a 5-point scale $(1=$ never; $5=$ always $)$.

Monitoring. Mothers' monitoring of their children's homework was measured using three items. (e.g., Do you make sure that your child has done his/her homework?). Answers were given on a 5-point scale $(1=$ never; $5=$ always $)$.

Autonomy granting. Mothers' autonomy granting behavior was assessed using three items (e.g., Do you trust that that the child takes care of his/her home assignments by himself/herself?). Answers were given on a 5 -point scale $(1=$ never; $5=$ always $)$.

\subsubsection{Teachers' Questionnaire}

Task persistence. In grades 2, 3, and 4, teachers evaluated the task-persistent behavior of each target child in their classes using the Behavioral Strategy Rating Scale (BSRS; Aunola, Nurmi, Parrila, \& Onatsu-Arvilommi, 2000; Onatsu-Arvilommi \& Nurmi, 2000; Zhang, Nurmi, Kiuru, Lerkkanen, \& Aunola, 2011). They were asked to consider how 
the child typically behaved in classroom situations and to rate his or her behavior on a 5-point scale $(1=$ not at all; $5=$ to a great extent $)$. Five statements were used, consisting of 2 positively worded items (e.g., Does the student actively attempt to solve even difficult situations and tasks?) and 3 negatively worded items (e.g., Does the student have a tendency to find something else to do instead of focusing on the task at hand?). When calculating the sum scores for task-persistent behavior, the negatively worded items were reversed.

\subsubsection{Children's Academic Performance}

Children's reading and math performance was tested in group situations at the end of grades 2,3 , and 4 .

Reading performance. Word reading fluency was tested by the test from the standardized national reading achievement test battery (ALLU; Lindeman, 1998). In Grades 2 and 4, form B with small letters was used. In Grade 3, form A with small letters was used. In the word reading test, children were asked to select the correct word from four phonologically similar alternatives and link it to a picture by drawing a line between the two. A maximum of 80 trials can be attempted within the test duration. The score is the number of correct responses within the time limit. In our study, a two-minute time limit was used. According to the test manual (Lindeman, 1998), the Kuder-Richardson reliability, a measure of internal consistency for dichotomous variables, was .97 for form B and .97 for form A. The alternate-form reliability between forms A and B was .84.

Math performance. Math performance was assessed by the Basic Arithmetic Test (BAT; Räsänen \& Aunola, 2007; see also Räsänen, Salminen, Wilson, Aunio, \& Dehaene, 2009) which consists of 14 addition and 14 subtraction tasks. A maximum of 28 trials is permitted within the test duration (a three-minute time limit). The score is the total number of correct answers (maximum 28 points). The items were identical in Grades 2 to 3 , but in Grade 4 more difficult items were added to the task to avoid a ceiling effect. The high 
test-retest correlations between the grades (see Table 2) indicated that adding the new items did not change the test significantly. The task difficulty increases gradually across the test, and it provides a combined measure of the speed and accuracy of the arithmetic procedures (Zhang et al., 2014).

A mean value of the standardized scores (Z-scores) of reading and math performance was used in the following analyses as an indicator of academic performance.

\subsection{Data Analysis}

A path model was constructed to answer the research questions. The model included mean-scores of the variables of maternal homework assistance (help, monitoring, and autonomy granting), children's task persistence, and their academic skills, followed across 3 time-points. To construct the path model, we included the stabilities of the same constructs across all three time points. We also specified the cross-lagged paths for the three variables of maternal homework assistance to predict children's task persistence and skills at the subsequent time point (across Grades 2 and 3 and across Grades 3 and 4). Also, we specified the cross-lagged paths for children's task persistence and skills to predict the variables of maternal homework assistance at the subsequent time-point (across Grades 2 and 3 and across grades 3 and 4). Also, the concurrent associations between all variables within the same time point were estimated. Finally, we estimated all indirect effects of measures in Grade 2 on measures in Grade 4, with a particular focus on the indirect effects of parental assistance in Grade 2 on skills in Grade 4 and skills in Grade 2 on parental homework assistance in Grade 4 via task persistence in Grade 3.

All the analyses were conducted using the Mplus statistical package (version 7.3). Little's MCAR test showed that the data was missing not completely-at-random, $\chi^{2}$ $(4795)=5403.513, p<.001$. We assumed, therefore, that the data was missing at random. When the data is assumed to be missing at random, Mplus uses full information maximum 
likelihood (FIML) approach. This approach to missing values uses all information that is available on variables of the model to estimate the model without imputing data. Because the distributions of the variables were skewed, the model parameters were estimated using the MLR estimator. The MLR estimator produces standard errors and chi-square test statistics for missing data with non-normal outcomes (Muthen \& Muthen, 1998-2010).

The participating children came from 126 classes (= clusters). The intraclass correlations $(I C C s)$ for all study variables varied from .001 $(p=.997)$ to $.164(p=.017)$, indicating some variation due to the nesting of the data. As at least part of the data varied depending on the class, we used "TYPE = complex" function of Mplus to account for the nested structure of our data. For all the models, goodness-of-fit was evaluated using four indicators: the Bentler (1990) comparative fit index (CFI), the Tucker-Lewis Index (TLI), the Root Mean Square Error of Approximation (RMSEA), and the Standardized Root Mean Square Residual (SRMR). According to Hu and Bentler (1999), TLI and CFI values above .95 , RMSEA values below .06, and SRMR values near .08 indicate a good model fit to the data. Only CFI and TLI values below .90, and RMSEA and SRMR values above .10 are considered indicators of a poor model fit.

\section{Results}

Descriptive statistics of the study variables are presented in Table 1. Zero-order correlations among all study variables are presented in Table 2.

\section{--- TABLES 1 AND 2 AROUND HERE ---}

The path model that we specified according to the procedure described in section 2.3 had a non-satisfactory model fit $(C F I=.93, T L I=.82, R M S E A=.11, S R M R$ $=.05)$. However, after a careful investigation of the modification indices, we discovered that specifying another stability path between autonomy granting in grade 2 and grade 4 would significantly improve the model. After this modification, the model obtained a good model fit 
$(C F I=.96, T L I=.90, R M S E A=.080, S R M R=.040)$. Thus, no other modifications were implemented. The results of the final model are presented in Figure 1 and in Table 3.

First, the results for the extent to which mothers' homework assistance predict children's task-persistent behavior showed that maternal autonomy granting predicted children's task persistence positively, and maternal help predicted children's task persistence negatively from grade 2 to grade 3: The more autonomy granting mothers reported, the more task persistence on behalf of their students teachers reported later on, and, on the contrary, the more mothers reported helping their children in homework, the less task persistence on behalf of their students teachers reported later on. However, neither mothers' help nor autonomy granting predicted children's teacher-reported task persistence from grade 3 to grade 4. Moreover, mother-reported monitoring did not predict children's teacher-reported task persistence later on at any measurement point.

Second, the results concerning the extent to which children's teacher-reported task-persistent behavior predicted mothers' reported homework assistance showed that children's task persistence positively predicted mothers' autonomy granting both from grade 2 to grade 3 and from grade 3 to grade 4: The more task persistence teachers reported children to exhibit, the more autonomy granting their mothers reported later on. In the case of both maternal help and monitoring the results showed that children's task persistence did not predict mothers' reported help or monitoring from grade 2 to grade 3 , but from grade 3 to grade 4 task avoidance was a negative predictor of both help and monitoring: The more task persistence teachers reported children to exhibit in grade 3, the less mothers reported helping or monitoring them in grade 4. 
Finally, to answer the third research question we investigated the indirect effects between mothers' homework assistance and children's skills via children's task persistence. The results showed, first, that mothers' autonomy granting in grade 2 had a marginally significant indirect effect on children's performance in grade 4 through children's task persistence in grade 3 (standardized indirect estimate $\beta=.02$, S.E. $=.01, p=.06$ ).

Second, also mothers' help in grade 2 had a marginally significant indirect effect on children's performance in grade 4 via children's task persistence in grade 3 (standardized indirect estimate $\beta=-.01, S . E .=.01, p=.08)$. Finally, the indirect effect of mothers' monitoring in grade 2 on children's performance in grade 4 through children's task persistence in grade 3 was not significant (standardized indirect estimate $\beta=.01$, S.E. $=.01$, $p=.18)$. The indirect effects from children's performance in grade 2 on homework assistance in grade 4 via task persistence in grade 3 did not reach statistical significance (standardized indirect estimate $\beta=-.01$, S.E. $=.01, p=.72$ for help; standardized indirect estimate $\beta=$ -.01, S.E. $=.01, p=.71$ for monitoring, standardized indirect estimate $\beta=.01$, S.E. $=.01, p$ $=.72$ for autonomy granting).

As additional analyses, separate models for each type of homework assistance were carried out to see whether the results would differ from the model where all three types of assistance were modeled simultaneously. Because the results were very similar, only the model where all assistance types were simultaneously analyzed is reported.

\section{Discussion}

The present study aimed at examining the extent to which the three types of self-reported maternal homework assistance, that is, help, monitoring and autonomy granting, and children's teacher-rated task persistence are longitudinally related from grade 2 to grade 4 of elementary school. The results showed, first, that mothers' autonomy granting in grade 2 predicted an increase and mothers' help in grade 2 predicted a decrease in children's task- 
persistent behavior in grade 3, whereas monitoring did not contribute to task persistence at all. In turn, task-persistent behavior was found to predict an increase in mothers' autonomy granting both from grade 2 to grade 3 and from grade 3 to grade 4, and a decrease in mothers' help and monitoring from grade 3 to grade 4. Furthermore, tentative support was found for the hypothesis that children's task persistence may play a role in the relationship between maternal homework assistance and children's performance.

Overall, the findings of the present study showed that even though maternal assistance in homework situations may usually be provided with an aim to positively contribute to child's schooling, the different types of maternal homework practices during early school years were, actually, differentially related to children's task-persistent behavior later on (Hypothesis 1). It was found, first, that self-reported maternal autonomy granting in grade 2 predicted a higher level of children's teacher-rated task persistence in grade 3 , and self-reported mothers' help in grade 2 predicted a lower level of teacher-rated task persistence in grade 3 . These results are well in line with the arguments derived from the SDT: Child's senses of autonomy and competence are among the crucial elements in regard to self-regulated behavior (Ryan \& Deci, 2000), and the different types of homework assistance may differently satisfy children's needs for autonomy and competence (Deci \& Ryan, 2008; Ryan \& Deci, 2000; see also Aunola et al., 2013; Deci et al., 1991). With autonomy granting, that is, by allowing the child to take care of his or her homework independently, mother is communicating her trust in the child's abilities to do so and providing feelings of individual control to the child, which, then, increases the effort and persistence that the child invests in challenging tasks (Pomerantz et al., 2007). Helping, in contrast, means that mothers are directly involved in their children's homework, and, therefore, it might foster children's feelings of mistrust from their mothers (see also Gonida \& Cortina, 2014) or incompetence and low beliefs in their ability to solve the tasks they think 
they should be able to solve autonomously (e.g., Ng et al., 2004; Pomerantz et al., 2007). This, then, could lead to a lower level of task persistence in learning situations (for other motivational outcomes, see Dumont et al., 2014; Gonida \& Cortina, 2014; Grolnick, 2003). The study by Silinskas and Kikas (2017) also previously found an association between parental control in homework situations and students' lack of task persistence within grade 6 but they did not examine parental control longitudinally. In turn, another study by Kikas and Silinskas (2016) showed that parental help in grade 1 did not predict later task persistence in grade 2 but in this longitudinal study they did not analyze the effects of parental autonomy granting. Therefore, the present study adds to the previous understanding of the role of maternal homework assistance by showing the effects of both mothers' autonomy granting and help on children's task persistence longitudinally.

Parental monitoring, in turn, has been previously found to have a less detrimental effect on children's skill development (Silinskas et al., 2015). In line with these previous findings, the present study showed that self-reported parental monitoring did not contribute to children's later persistence. It is possible that with this kind of assistance where mothers check that the child's homework is done and correct, they do not communicate any particularly strong positive or negative cue about their children's ability or trust/mistrust in their children's abilities to complete homework on their own. This might suggest that parental monitoring can indeed act as a neutral way of involving and showing interest in children's schooling.

Further, it was found that it is not only mothers' assistance in homework situations that influences children's task persistence but also children's task-persistent behavior evokes certain kind of maternal behavior in these situations (Hypothesis 2). The more teachers reported children to exhibit task persistence at school in grades 2 and 3 , the more mothers reported providing them autonomy with homework in grades 3 and 4; and the 
less teachers reported children to show task persistence in grade 3, the more mothers reported helping and monitoring them in grade 4. These results are not surprising: Child's persistent behavior at school and related feedback from the teacher may help mothers to feel more confident about the children's willingness and ability to independently take care of their homework, which then encourages mothers to grant autonomy (Dumont et al., 2014). In contrast, less persistent behavior (such as task avoidance) may lead mothers to think that more direct involvement and guidance is needed. These results add to previous literature in an important way by showing that, in addition to previously suggested factors such as children's achievement level (e.g., Silinskas et al., 2013; 2015) and parent's goals and efficacy beliefs for their children (Gonida \& Cortina, 2014), children's task-persistent behavior is another important factor contributing to parental choices of adopting certain types of homework involvement.

Overall, these findings indicate that the relations between homework assistance and children's task-persistent behavior cannot be interpreted as effects going only in one direction but rather as a continuous interplay between the child and the parent responsible for guiding and supporting the child (Sameroff, 2010). Because the strength of associations was found to differ to some extent between different time points, the findings of the present study also raise some additional questions about the dynamic interplay between the child and the parent: For example, parental help and autonomy support contributed to children's taskpersistent behavior from grade 2 to grade 3 , but not from grade 3 to grade 4 . It is possible that the importance of parental actions varies with child's age, as is suggested by some previous studies that have found declines in the amount of parental autonomy support and control (Gonida \& Cortina, 2014) and overall parental involvement in children's education (e.g., Eccles \& Harold, 1996) during the school years. In the beginning of school, parents are more involved in their children's schooling, which may cause homework assistance to have a 
stronger impact on children's task-persistent behavior during the earlier years, whereas later on this involvement decreases and parents start to provide their assistance more as a reaction to children's behavior and achievement. This was also supported by the results: children's teacher-rated task persistence predicted both help and monitoring from grade 3 to grade 4 (but not yet from grade 2 to grade 3 ). In future, there is an evident need for longitudinal research focusing on the reciprocal development of these factors.

The final aim of the present study was to examine whether children's task persistence plays a role in the relationship between maternal homework-related practices and children's performance. Some tentative support for this (Hypothesis 3) was found. There were weak indirect effects from mother's help and autonomy granting in Grade 2 on children's performance in Grade 4 via children's task persistence in Grade 3: The more mothers reported helping their children and the less they reported granting autonomy to their children in homework situations, the less task persistence the children exhibited based on teacher-reports and, consequently, the poorer their performance was later on. This result gives important insights into previous literature (see Patall et al., 2008), which has suggested that parental involvement in homework influences children's academic performance by affecting their motivation. This possibility has been seldom empirically tested (as an exception, see Kikas \& Silinskas, 2016, for literacy skills, parental help and task persistence). The findings concerning the role of task-persistent behavior may also at least partly explain why parental homework assistance has in some studies found to benefit and in some studies to harm children's skill development. Therefore, even though the present study found only weak effects, they provide tentative support for the previous suggestions and, thus, encourage future studies to focus on the mediating role of task persistence and other motivational variables with larger samples and different educational contexts. 
There are several limitations that need to be taken into account when interpreting the results of the present study. First, homework assistance was measured by mothers' self-reports as the frequency of different types of assistance instead of the quality of assistance. It would be informative to include also children's own perceptions of how much and what kind of assistance they receive from their parents and whether they find it adequate (Nunez et al., 2015; Silinskas \& Kikas, 2017). Second, both homework assistance and task persistence were measured as general constructs, and no information of subject-specific homework assistance or task persistence was available. So far, only a few studies have focused on specific subjects (Dumont et al., 2012; Silinskas \& Kikas, 2017; Trautwein \& Lüdke, 2009) even though parental assistance in homework can vary depending on the subject. In relation to this, there was a slight unbalance in the measures of autonomy granting and monitoring versus help because the items for monitoring and autonomy granting did not include subject-specific items, whereas maternal help included one item regarding help in reading and one item regarding help in mathematics. In order to be sure that this unbalance did not affect any of the findings, sensitivity analysis was conducted, that is, a model without these two domain-specific items was run. This did not change the results. Finally, children's task persistence was measured according to their behavior at school, and homework assistance was defined as actions related to homework situations at home. Even though teachers' and parents' ratings of students' task-persistent behavior have been found to be related (e.g., Georgiou, Hirvonen, Manolitsis, \& Nurmi, 2017; Zhang et al., 2011), it is possible that children's motivational behavior differs to some extent in different contexts.

The findings of the present study suggest that there is a continuous interplay between maternal homework assistance and children's task-persistent behavior. Different types of assistance affect children's task-persistent behavior in the classroom in different ways, and mothers also adjust their homework assistance according to children's behavior. 
This interplay may, then, contribute to children's further skill development. Teachers are the key persons in giving guidance to parents on how to support their children with their individual needs in homework situations. Parents might benefit from concrete examples of different types of homework assistance and their potential influence on children's motivation and task-persistent behavior. Moreover, family meetings with the teacher where parents and child participate together and discuss the learning goals and best ways of supporting the child's learning process at home would help both the parents and the child to find appropriate ways to do homework with the support of the parents.

\section{Acknowledgements}

This study was funded by personal funding for the first author from the Academy of Finland (\#265817), and other grants from the same funding agency for the project (Nr. 268586 for 2013-2017, 266851 for 2013-2017, and 292466 for 2015-2019) and for other authors (\#294970, \# 277299, and \# 296082). 


\section{References}

Aunola, K., Nurmi, J. -E., Lerkkanen, M.-K., \& Rasku-Puttonen, H. (2003), The role of achievement-related behaviors and parental beliefs in children's mathematical performance. Educational Psychology, 23, 403-421. doi: 10.1080/01443410303212

Aunola, K., Nurmi, J. -E., Niemi, P., Lerkkanen, M.-K., \& Rasku-Puttonen, H. (2002). Developmental dynamics of achievement strategies, reading performance, and parental beliefs. Reading Research Quarterly, 37, 310-327. doi: 10.1598/RRQ.37.3.3

Aunola, K., Nurmi, J.-E., Parrila, R., \& Onatsu-Arvilommi, T. (2000). Behavioral Strategy Rating Scale. Jyväskylä, Finland: University of Jyväskylä.

Aunola, K., Viljaranta, J., Lehtinen, E., \& Nurmi, J.-E. (2013). The role of maternal support of competence, autonomy and relatedness in children's interests and mastery orientation. Learning and Individual Differences, 25, 171-177. doi:10.1016/j.lindif.2013.02.002

Bentler, P. M. (1990). Comparative fit indexes in structural models. Psychological Bulletin, 99, 229-246. doi:10.1037/0033-2909.107.2.238

Cooper, H., Lindsay, J. J., \& Nye, B. (2000). Homework in the home: How student, family, and parenting-style differences relate to the homework process. Contemporary Educational Psychology, 25, 464-487. doi:10.1006/ceps.1999.1036

Deci, E. L., \& Ryan, R. M. (2008). Facilitating optimal motivation and psychological wellbeing across life's domains. Canadian Psychology, 49, 14-23. doi:10.1037/07085591.49 .1 .14

Deci, E. L., Schwartz, A. J., Sheinman, L., \& Ryan, R. M. (1981). An instrument to assess adults' orientations toward control versus autonomy with children: Reflections on intrinsic motivation and perceived competence. Journal of Educational Psychology, 73, 642-650. doi:10.1037/0022-0663.73.5.642 
Deci, E. L., Vallerand, R. J., Pelletier, L. G., \& Ryan, R. M. (1991). Motivation and education: The self-determination perspective. Educational Psychologist, 26, 325-346. doi:10.1080/00461520.1991.9653137

Dumont, H., Trautwein, U., Lüdtke, O., Neumann, M., Niggli, A., \& Schnyder, I. (2012). Does parental homework involvement mediate the relationship between family background and educational outcomes? Contemporary Educational Psychology, 37, 5569. doi:10.1016/j.cedpsych.2011.09.004

Dumont, H., Trautwein, U., Nagy, G., \& Nagengast, B. (2014). Quality of parental homework involvement: Predictors and reciprocal relations with academic functioning in the reading domain. Journal of Educational Psychology, 106, 144-161. doi:10.1037/a0034100

Eccles, J. S., Adler, T. F., Futterman, R., Goff, S. B., Kaczala, C. M., Meece, J., \& al., e. (1983). Expectancies, values and academic behaviors. In J. T. Spence (Ed.), Achievement and achievement motives: Psychological and sociological approaches (pp. 75-146). San Francisco, CA: Freeman.

Eccles, J.S. (2005). Subjective Task Value and the Eccles et al. Model of AchievementRelated Choices. In A.J. Elliot \& C.S. Dweck, (Eds.) Handbook of Competence and Motivation (pp. 105-121). New York: The Guilford Press.

Eccles, J., \& Harold, R. (1996). Family involvement in children's and adolescents' schooling. In A. Booth \& J. Dunn (Eds.), Family-school links: How do they affect educational outcomes (pp. 3-34). Hillsdale, NJ: Erlbaum.

Georgiou, G. K., Hirvonen, R., Manolitsis, G., \& Nurmi, J.-E. (2017). Cross-lagged relations between teacher and parent ratings of children's task avoidance and different literacy skills. British Journal of Educational Psychology. doi:10.1111/bjep.12158 
Gonida, E. N., \& Cortina, K. S. (2014). Parental involvement in homework: Relations with parent and student achievement-related motivational beliefs and achievement. British Journal of Educational Psychology, 84, 376-396. doi:10.1111/bjep.12039

Grolnick, W. S. (2003). The psychology of parental control: How well-meant parenting backfires. Mahwah, NJ: Erlbaum.

Grolnick, W. S., \& Ryan, R. M. (1989). Parent styles associated with children's selfregulation and competence at school. Journal of Educational Psychology, 81, 143-154. http://dx.doi.org/10.1037/0022-0663.81.2.143

Hill, N. E., \& Tyson, D. F. (2009). Parental involvement in middle school: A meta-analytic assessment of the strategies that promote achievement. Developmental Psychology, 45, 740-763. doi:10.1037/a0015362

Hirvonen, R., Georgiou, G., Lerkkanen, M.-K., Aunola, K., \& Nurmi, J.-E. (2010). Taskfocused behaviour and literacy development: A reciprocal relationship. Journal of Research in Reading, 33, 302-319. doi:10.1111/j.1467-9817.2009.01415.x

Hoover-Dempsey, K.V., \& Sandler, H. M. (1997). Why do parents become involved in their children's education? Review of Educational Research, 67, 3-42.

Hu, L.-T., \& Bentler, P. M. (1999). Cutoff criterion for fit indexes in covariance structure analysis: conventional criteria versus new alternatives. Structural Equation Modeling, 6, 1-55. doi:10.1080/10705519909540118

Jeynes, W. H. (2005). A meta-analysis of the relation of parental involvement to urban elementary school student academic achievement. Urban Education, 40, 237-269. doi:10.1177/0042085905274540

Kikas, E., \& Silinskas, G. (2016). Task persistence mediates the effect of children's literacy skills on mothers' academic help. Educational Psychology, 36, 975-991. doi:10.1080/01443410.2015.1045836 
Leone, C. M., \& Richards, M. H. (1989). Classwork and homework in early adolescence: The ecology of achievement. Journal of Youth and Adolescence, 18, 531-548. doi:10.1207/s15326985ep3001_3

Lindeman, J. (1998). ALLU—Ala-asteen lukutesti [Reading test for primary school]. Turku, Finland: University of Turku.

Moorman, E. A., \& Pomerantz, E. M. (2008). The role of mothers' control in children's mastery orientation: A time frame analysis. Journal of Family Psychology, 22, 734-741. doi:10.1037/0893-3200.22.5.734

Moroni, S., Dumont, H., Trautwein, U., Niggli, A., \& Baeriswyl, F. (2015). The need to distinguish between quantity and quality in research on parental involvement: The example of parental help with homework. Journal of Educational Research, 108, 417-431. doi: $10.1080 / 00220671.2014 .901283$

Muthén, L. K., \& Muthén, B. O. (1998-2010). Mplus user's guide. Los Angeles, CA: Muthén \& Muthén.

Ng, F. F.-Y., Kenney-Benson, G. A., \& Pomerantz, E. M. (2004). Children's achievement moderates the effects of mothers' use of control and autonomy support. Child Development, 75, 64-780. doi:10.1111/j.1467-8624.2004.00705.x

Núñez, J. C., Suárez, N., Rosário, P., Vallejo, G., Valle, A., \& Epstein, J. L. (2015). Relationships between perceived parental involvement in homework, student homework behaviors, and academic achievement: Differences among elementary, junior high, and high school students. Metacognition and Learning, 10, 375-406. doi:10.1007/s11409-015$9135-5$

Nurmi, J.-E. (2012). Students' characteristics and teacher-child relationships in instruction: A meta-analysis. Educational Research Review, 7, 177-197. doi:10.1016/j.edurev.2012.03.001 
Onatsu-Arvilommi, T., \& Nurmi, J.-E. (2000). The role of task-avoidant and task-focused behaviors in the development of reading and mathematical skills during the first school year: A cross-lagged longitudinal study. Journal of Educational Psychology, 93, 478-491. doi:10.1037/0022-0663.92.3.478

Patall, E. A., Cooper, H., \& Robinson, J. C. (2008). Parent involvement in homework: A research synthesis. Review of Educational Research, 78, 1039-1101. doi:10.3102/0034654308325185

Pezdek, K., Berry, T., \& Renno, P. A. (2002). Children's mathematics achievement: The role of parents' perceptions and their involvement in homework. Journal of Educational Psychology, 94, 771-777. doi:10.1037/0022-0663.94.4.771

Pomerantz, E. M., \& Eaton, M. M. (2001). Maternal intrusive support in the academic context: Transactional socialization processes. Developmental Psychology, 37, 174-186. doi:10.1037/0012-1649.37.2.174

Pomerantz, E. M., Moorman, E. A., \& Litwack, S. D. (2007). The how, whom, and why of parents' involvement in children's academic lives: More is not always better. Review of Educational Research, 77, 373-410. doi:10.3102/003465430305567

Räsänen, P., \& Aunola, K. (2007). Test of arithmetic skills. [Unpublished test material, First Steps study]. Jyväskylä, Finland: University of Jyväskylä.

Räsänen, P., Salminen, J., Wilson, A. J., Aunio, P., \& Dehaene, S. (2009). Computer-assisted intervention for children with low numeracy skills. Cognitive Development, 24, 450-472. doi:10.1016/j.cogdev.2009.09.003

Ryan, R. M., \& Deci, E. L. (2000). Self-determination theory and the facilitation of intrinsic motivation, social development, and well-being. American Psychologist, 55, 68-78. doi:10.1037/0003-066X.55.1.68 
Sameroff, A. (2010). A unified theory of development: A dialectic integration of nature and nurture. Child Development, 81, 6-22. doi:10.1111/j.1467-8624.2009.01378.x

Scarr, S., \& McCartney, K. (1983). How people make their own environments: A theory of genotype $\rightarrow$ environment effects. Child Development, 54, 424-435. doi:10.2307/1129703

Shumow, L. (1998). Promoting parental attunement to children's mathematical reasoning through parent education. Journal of Applied Developmental Psychology, 19, 109-127. doi:10.1016/S0193-3973(99)80031-8

Silinskas, G., \& Kikas, E. (2017). Parental involvement in math homework: Links to children's performance and motivation. Scandinavian Journal of Educational Research. doi:10.1080/00313831.2017.1324901.

Silinskas, G., Kiuru, N., Aunola, K., Lerkkanen, M.-K., \& Nurmi, J.-E. (2015). The developmental dynamics of children's academic performance and mothers' homeworkrelated affect and practices. Developmental Psychology, 51, 419-433. doi:10.1037/a0038908

Silinskas, G., Niemi, P., Lerkkanen, M.-K., \& Nurmi, J.-E. (2013). Children's poor academic achievement evokes parental homework assistance-but does it help? International Journal of Behavioral Development, 37, 44-56. doi:10.1177/0165025412456146

Soenens, B., Vansteenkiste, M., Lens, W., Luyckx, K., Goossens, L., Beyers, W., \& Ryan, R.M. (2007). Conceptualizing parental autonomy support: Adolescent perceptions of promotion of independence versus promotion of volitional functioning. Developmental Psychology, 43, 633-646. doi:10.1037/0012-1649.43.3.633

Statistics Finland (2010). Education 2010. Retrieved December 27, 2010, from http://www.stat.fi/til/vkour/2009/vkour_2009_2010-12-03 tie_001_en.html.

Trautwein, U., \& Lüdtke, O. (2009). Predicting homework motivation and homework effort in six school subjects: The role of person and family characteristics, classroom factors, and 
school track. Learning and Instruction, 19, 243-258.

doi:10.1016/j.learninstruc.2008.05.001

Van der Kaap-Deeder, J., Vansteenkiste, M., Soenens, B., Mabbe, E. (2015). Children's daily well-being: The role of mothers', teachers', and siblings' autonomy support and psychological control. Developmental Psychology, 53, 237-251. doi: 10.1037/dev0000218

Van Petegem, S., Zimmer-Gembeck, M.J., Soenens, B., ..., \& Zimmermann, G. (2017). Does parenting context modify adolescents' appraisals and coping with a situation of parental regulation? The case of autonomy-supportive parenting. Journal of Child and Family Studies. doi: 10.1007/s10826-017-0758-9

Xu, J., Fan, X, Du, J., \& He, M. (2017). A study of the validity and reliability of the Parental Homework Support Scale. Measurement, 95, 93-98. doi:

10.1016/j.measurement.2016.09.045

Zhang, X., Koponen, T., Rasanen, P., Aunola, K., Lerkkanen, M., \& Nurmi, J.-E. (2014). Linguistic and spatial skills predict early arithmetic development via counting sequence knowledge. Child Development, 85, 1091-1107. doi: 10.1111/cdev.12173

Zhang, X., Nurmi, J.-E., Kiuru, N., Lerkkanen, M.-K., \& Aunola, K. (2011). A teacher-report measure of children's task-avoidant behavior: A validation study of the Behavioral Strategy Rating Scale. Learning and Individual Differences, 21, 690-698. doi:10.1016/j.lindif.2011.09.007 


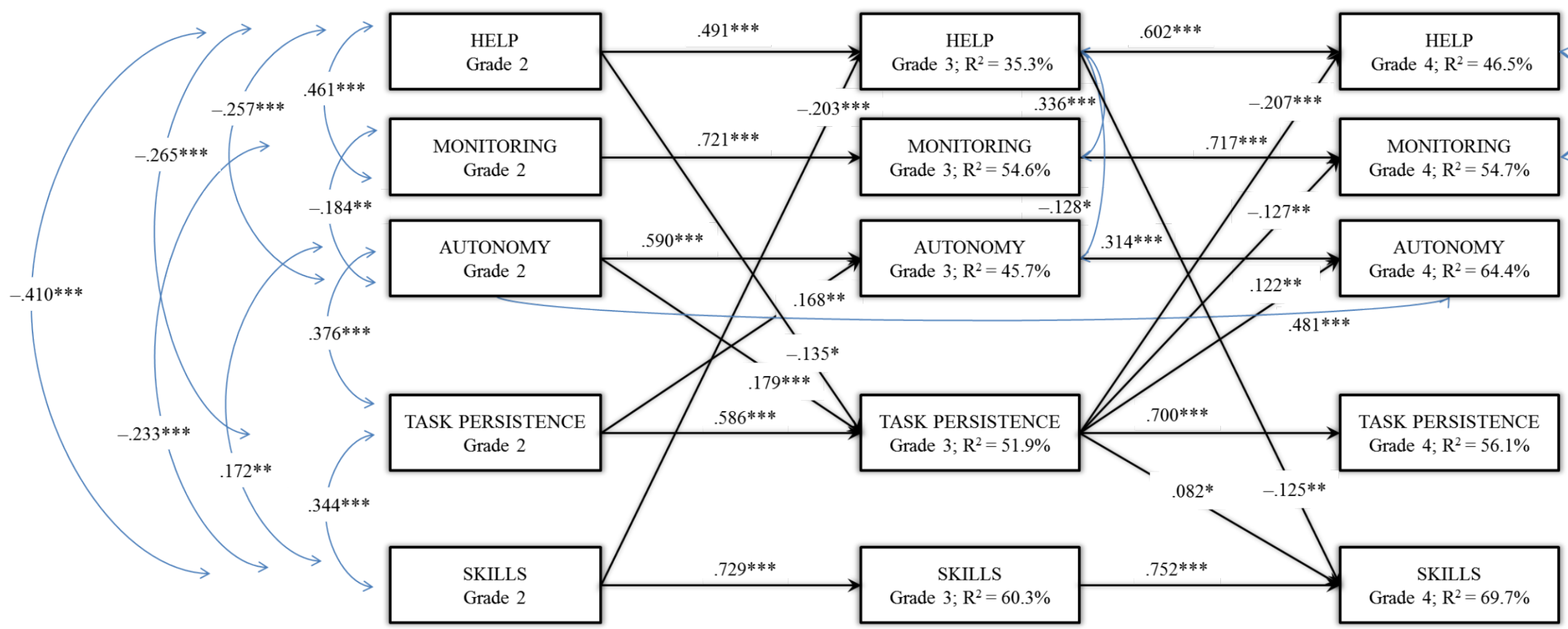

Figure 1. Longitudinal associations between maternal homework assistance (help, monitoring, and autonomy), children's task persistent behavior, and their academic skills: Standardized solution.

$* p<.05 ; * * p<.01 ; * * * p<.001$. 
Table 1

Psychometric Properties of All Study Variables

\begin{tabular}{|c|c|c|c|c|c|c|c|}
\hline \multirow[b]{2}{*}{ Variable } & \multirow[b]{2}{*}{$n$} & \multirow[b]{2}{*}{$M$} & \multirow[b]{2}{*}{$S D$} & \multirow[b]{2}{*}{ Reliability } & \multicolumn{2}{|c|}{ Range } & \multirow[b]{2}{*}{ Skewness } \\
\hline & & & & & Potential & Actual & \\
\hline \multicolumn{8}{|l|}{ Mother-reports } \\
\hline Help (Grade 2) & 288 & 2.92 & .67 & .74 & $1-5$ & $1-5$ & .85 \\
\hline Help (Grade 3) & 276 & 2.73 & .60 & .66 & $1-5$ & $1-5$ & .69 \\
\hline Help (Grade 4) & 246 & 2.62 & .54 & .60 & $1-5$ & $1-4.75$ & .34 \\
\hline Monitoring (Grade 2) & 289 & 3.97 & .91 & .83 & $1-5$ & $1.33-5$ & -.53 \\
\hline Monitoring (Grade 3) & 275 & 3.55 & .88 & .82 & $1-5$ & $1.33-5$ & -.12 \\
\hline Monitoring (Grade 4) & 246 & 3.32 & .81 & .81 & $1-5$ & $1-5$ & -.16 \\
\hline Autonomy granting (Grade 2) & 288 & 3.85 & .82 & .85 & $1-5$ & $1-5$ & -.63 \\
\hline Autonomy granting (Grade 3) & 275 & 3.80 & .84 & .85 & $1-5$ & $1.33-5$ & -.48 \\
\hline Autonomy granting (Grade 4) & 246 & 3.91 & .81 & .81 & $1-5$ & $1.67-5$ & -.64 \\
\hline \multicolumn{8}{|l|}{ Teacher-reports } \\
\hline Children's task-persistence (Grade 2) & 317 & 3.56 & 1.04 & .92 & $1-5$ & $1-5$ & .39 \\
\hline Children's task-persistence (Grade 3) & 298 & 3.65 & 1.08 & .92 & $1-5$ & $1-5$ & .52 \\
\hline Children's task-persistence (Grade 4) & 272 & 3.75 & 1.02 & .93 & $1-5$ & $1-5$ & .66 \\
\hline \multicolumn{8}{|l|}{ Child-tests } \\
\hline Reading (Grade 2) & 365 & 24.78 & 7.51 & $.93^{\mathrm{a}}$ & $0-80$ & $3-58$ & .39 \\
\hline Reading (Grade 3) & 362 & 35.58 & 8.61 & $.94^{\mathrm{a}}$ & $0-80$ & $12-58$ & -.28 \\
\hline Reading (Grade 4) & 346 & 36.90 & 9.11 & $.95^{\mathrm{a}}$ & $0-80$ & $0-64$ & -.11 \\
\hline Math (Grade 2) & 364 & 16.26 & 4.90 & $.89^{\mathrm{a}}$ & $0-28$ & $2-28$ & -.19 \\
\hline Math (Grade 3) & 362 & 19.69 & 4.76 & $.86^{\mathrm{a}}$ & $0-28$ & $4-28$ & -.75 \\
\hline Math (Grade 4) & 346 & 17.05 & 4.10 & $.85^{\mathrm{a}}$ & $0-28$ & $2-25$ & -.74 \\
\hline
\end{tabular}

Note. ${ }^{a}$ The Kuder-Richardson reliability, a measure of internal consistency for dichotomous variables. 
Table 2

Correlations between All Study Variables

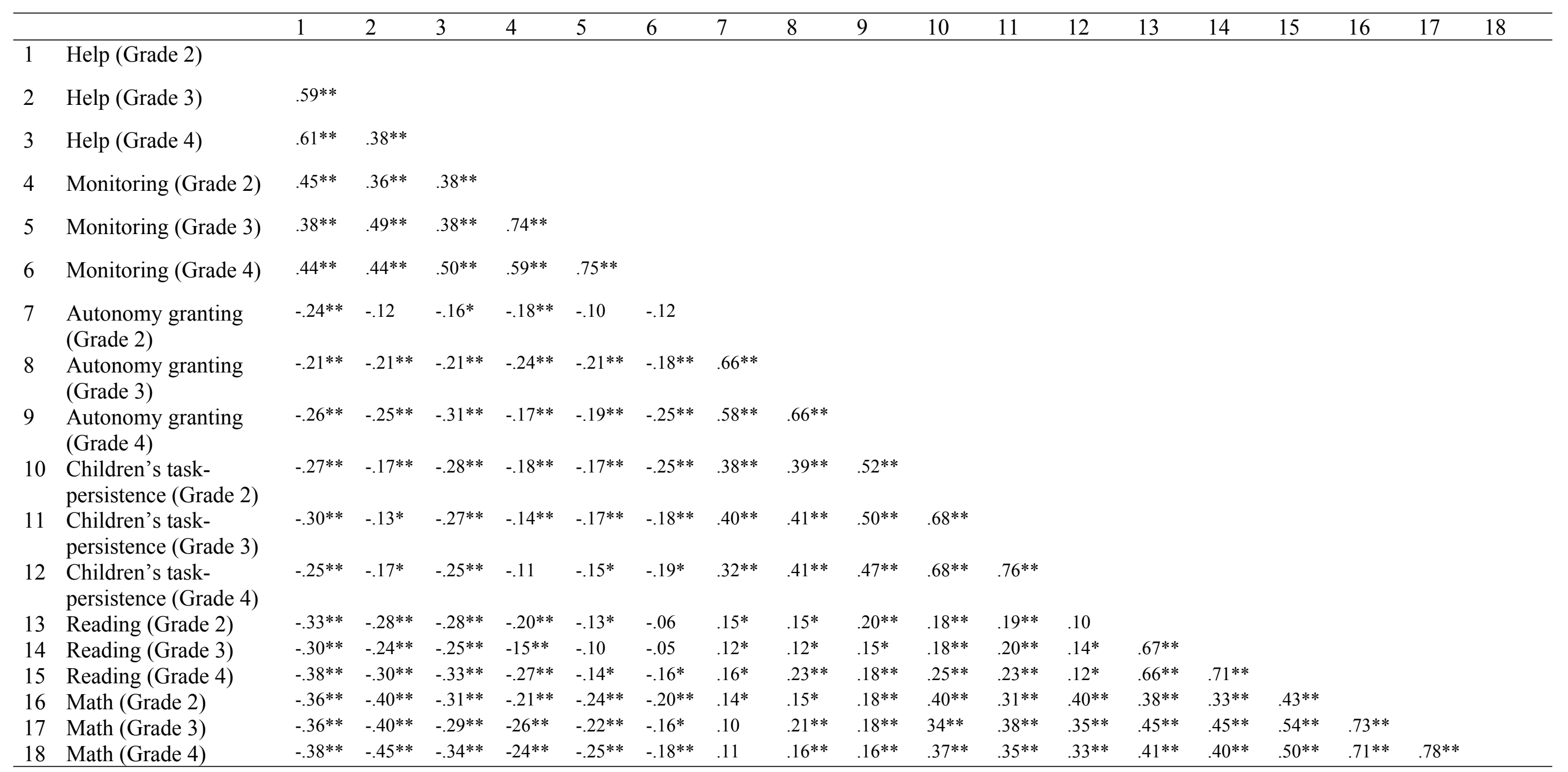


Note. ${ }^{*} p<.05 ; * * p<.01$. 
Table 3

Standardized and Unstandardized Estimates for the Final Model $(N=365)$

\begin{tabular}{|c|c|c|c|c|c|c|c|}
\hline & & & $\begin{array}{l}\text { Unstand. } \\
\text { estimate }\end{array}$ & $S E$ & $\begin{array}{c}\text { Stand. } \\
\text { estimate }\end{array}$ & $S E$ & $p$-value \\
\hline \multicolumn{8}{|l|}{ Stability paths } \\
\hline Help (Grade 2) & $\longrightarrow$ & Help (Grade 3) & .484 & .064 & .491 & .053 & $<.001$ \\
\hline Help (Grade 3) & $\longrightarrow$ & Help (Grade 4) & .560 & .056 & .602 & .046 & $<.001$ \\
\hline Monitoring (Grade 2) & $\longrightarrow$ & Monitoring (Grade 3) & .733 & .047 & .721 & .034 & $<.001$ \\
\hline Monitoring (Grade 3) & $\longrightarrow$ & Monitoring (Grade 4) & .675 & .046 & .717 & .034 & $<.001$ \\
\hline Autonomy (Grade 2) & $\longrightarrow$ & Autonomy (Grade 3) & .609 & .052 & .590 & .046 & $<.001$ \\
\hline Autonomy (Grade 3) & $\longrightarrow$ & Autonomy (Grade 4) & .321 & .064 & .314 & .060 & $<.001$ \\
\hline Autonomy (Grade 2) & $\longrightarrow$ & Autonomy (Grade 4) & .508 & .068 & .481 & .062 & $<.001$ \\
\hline Task persistence (Grade 2) & $\longrightarrow$ & Task persistence (Grade 3) & .608 & .051 & .586 & .051 & $<.001$ \\
\hline Task persistence (Grade 3) & $\longrightarrow$ & Task persistence (Grade 4) & .669 & .045 & .700 & .041 & $<.001$ \\
\hline Skills (Grade 2) & $\longrightarrow$ & Skills (Grade 3) & .752 & .040 & .729 & .028 & $<.001$ \\
\hline Skills (Grade 3) & $\longrightarrow$ & Skills (Grade 4) & .759 & .040 & .752 & .031 & $<.001$ \\
\hline \multicolumn{8}{|l|}{ Cross-lagged paths } \\
\hline Task persistence (Grade 2) & $\longrightarrow$ & Help (Grade 3) & .024 & .044 & .029 & .055 & .592 \\
\hline Skills (Grade 2) & $\longrightarrow$ & Help (Grade 3) & -.190 & .056 & -.203 & .057 & $<.001$ \\
\hline Task persistence (Grade 2) & $\rightarrow$ & Monitoring (Grade 3) & -.050 & .046 & -.053 & .050 & .286 \\
\hline Skills (Grade 2) & $\longrightarrow$ & Monitoring (Grade 3) & -.042 & .046 & -.038 & .042 & .360 \\
\hline
\end{tabular}




\begin{tabular}{|c|c|c|c|c|c|c|c|}
\hline Task persistence (Grade 2) & $\rightarrow$ & Autonomy (Grade 3) & .151 & .048 & .168 & .052 & .001 \\
\hline Skills (Grade 2) & $\longrightarrow$ & Autonomy (Grade 3) & .020 & .048 & .020 & .046 & .670 \\
\hline Help (Grade 2) & $\rightarrow$ & Task persistence (Grade 3) & -.172 & .070 & -.135 & .056 & .016 \\
\hline Monitoring (Grade 2) & $\longrightarrow$ & Task persistence (Grade 3) & .083 & .060 & .074 & .048 & .123 \\
\hline Autonomy (Grade 2) & $\longrightarrow$ & Task persistence (Grade 3) & .214 & .060 & .179 & .049 & $<.001$ \\
\hline Skills (Grade 2) & $\rightarrow$ & Task persistence (Grade 3) & .019 & .053 & .016 & .044 & .715 \\
\hline Help (Grade 2) & $\longrightarrow$ & Skills (Grade 3) & -.077 & .045 & -.071 & .041 & .082 \\
\hline Monitoring (Grade 2) & $\rightarrow$ & Skills (Grade 3) & -.008 & .035 & -.008 & .036 & .831 \\
\hline Autonomy (Grade 2) & $\rightarrow$ & Skills (Grade 3) & -.020 & .037 & -.019 & .036 & .593 \\
\hline Task persistence (Grade 2) & $\rightarrow$ & Skills (Grade 3) & .041 & .037 & .046 & .041 & .267 \\
\hline Task persistence (Grade 3) & $\rightarrow$ & Help (Grade 4) & -.150 & .033 & -.207 & .043 & $<.001$ \\
\hline Skills (Grade 3) & $\rightarrow$ & Help (Grade 4) & -.038 & .039 & -.044 & .046 & .334 \\
\hline Task persistence (Grade 3) & $\rightarrow$ & Monitoring (Grade 4) & -.108 & .039 & -.127 & .046 & .006 \\
\hline Skills (Grade 3) & $\longrightarrow$ & Monitoring (Grade 4) & -.001 & .044 & -.001 & .044 & .988 \\
\hline Task persistence (Grade 3) & $\longrightarrow$ & Autonomy (Grade 4) & .108 & .041 & .122 & .047 & .009 \\
\hline Skills (Grade 3) & $\longrightarrow$ & Autonomy (Grade 4) & .054 & .036 & .052 & .035 & .135 \\
\hline Help (Grade 3) & $\rightarrow$ & Task persistence (Grade 4) & .030 & .070 & .024 & .057 & .667 \\
\hline Monitoring (Grade 3) & $\longrightarrow$ & Task persistence (Grade 4) & -.008 & .054 & -.008 & .051 & .884 \\
\hline Autonomy (Grade 3) & $\longrightarrow$ & Task persistence (Grade 4) & .085 & .060 & .077 & .054 & .157 \\
\hline Skills (Grade 3) & $\longrightarrow$ & Task persistence (Grade 4) & .053 & .056 & .047 & .051 & .352 \\
\hline Help (Grade 3) & $\longrightarrow$ & Skills (Grade 4) & -.139 & .046 & -.125 & .042 & .003 \\
\hline
\end{tabular}




\begin{tabular}{|c|c|c|c|c|c|c|c|}
\hline Monitoring (Grade 3) & $\longrightarrow$ & Skills (Grade 4) & -.006 & .031 & -.006 & .032 & .847 \\
\hline Autonomy (Grade 3) & $\longrightarrow$ & Skills (Grade 4) & .003 & .039 & .003 & .039 & .937 \\
\hline Task persistence (Grade 3) & $\longrightarrow$ & Skills (Grade 4) & .071 & .030 & .082 & .035 & .017 \\
\hline \multicolumn{8}{|l|}{ Covariances/correlations } \\
\hline Help (Grade 2) & $\leftrightarrow$ & Monitoring (Grade 2) & .315 & .048 & .461 & .048 & $<.001$ \\
\hline Help (Grade 2) & $\leftrightarrow$ & Autonomy (Grade 2) & -.166 & .046 & -.257 & .066 & $<.001$ \\
\hline Help (Grade 2) & $\leftrightarrow$ & Task persistence (Grade 2) & -.197 & .047 & -.265 & .057 & $<.001$ \\
\hline Help (Grade 2) & $\leftrightarrow$ & Skills (Grade 2) & -.262 & .043 & -.410 & .049 & $<.001$ \\
\hline Monitoring (Grade 2) & $\leftrightarrow$ & Autonomy (Grade 2) & -.134 & .048 & -.184 & .063 & .003 \\
\hline Monitoring (Grade 2) & $\leftrightarrow$ & Task persistence (Grade 2) & -.082 & .056 & -.098 & .065 & .129 \\
\hline Monitoring (Grade 2) & $\leftrightarrow$ & Skills (Grade 2) & -.168 & .044 & -.233 & .059 & $<.001$ \\
\hline Autonomy (Grade 2) & $\leftrightarrow$ & Task persistence (Grade 2) & .297 & .047 & .376 & .053 & $<.001$ \\
\hline Autonomy (Grade 2) & $\leftrightarrow$ & Skills (Grade 2) & .117 & .036 & .172 & .051 & .001 \\
\hline Task persistence (Grade 2) & $\leftrightarrow$ & Skills (Grade 2) & .269 & .052 & .344 & .054 & $<.001$ \\
\hline Help (Grade 3) & $\leftrightarrow$ & Monitoring (Grade 3) & .125 & .026 & .336 & .054 & $<.001$ \\
\hline Help (Grade 3) & $\leftrightarrow$ & Autonomy (Grade 3) & -.050 & .025 & -.128 & .063 & .042 \\
\hline Help (Grade 3) & $\leftrightarrow$ & Task persistence (Grade 3) & .044 & .023 & .104 & .054 & .060 \\
\hline Help (Grade 3) & $\leftrightarrow$ & Skills (Grade 3) & -.015 & .020 & -.044 & .059 & .458 \\
\hline Monitoring (Grade 3) & $\leftrightarrow$ & Autonomy (Grade 3) & -.015 & .027 & -.038 & .072 & .595 \\
\hline Monitoring (Grade 3) & $\leftrightarrow$ & Task persistence (Grade 3) & .015 & .025 & .037 & .061 & .544 \\
\hline
\end{tabular}




\begin{tabular}{|c|c|c|c|c|c|c|c|}
\hline Monitoring (Grade 3) & $\leftrightarrow$ & Skills (Grade 3) & .025 & .021 & .077 & .064 & .231 \\
\hline Autonomy (Grade 3) & $\leftrightarrow$ & Task persistence (Grade 3) & .050 & .031 & .116 & .069 & .108 \\
\hline Autonomy (Grade 3) & $\leftrightarrow$ & Skills (Grade 3) & .023 & .020 & .068 & .058 & .248 \\
\hline Task persistence (Grade 3) & $\leftrightarrow$ & Skills (Grade 3) & .034 & .023 & .093 & .064 & .143 \\
\hline Help (Grade 4) & $\leftrightarrow$ & Monitoring (Grade 4) & .103 & .020 & .349 & .057 & $<.001$ \\
\hline Help (Grade 4) & $\leftrightarrow$ & Autonomy (Grade 4) & -.029 & .020 & -.107 & .074 & .151 \\
\hline Help (Grade 4) & $\leftrightarrow$ & Task persistence (Grade 4) & -.002 & .023 & -.006 & .072 & .937 \\
\hline Help (Grade 4) & $\leftrightarrow$ & Skills (Grade 4) & -.023 & .015 & -.094 & .061 & .125 \\
\hline Monitoring (Grade 4) & $\leftrightarrow$ & Autonomy (Grade 4) & -.030 & .028 & -.100 & .094 & .286 \\
\hline Monitoring (Grade 4) & $\leftrightarrow$ & Task persistence (Grade 4) & -.048 & .030 & -.135 & .081 & .095 \\
\hline Monitoring (Grade 4) & $\leftrightarrow$ & Skills (Grade 4) & -.025 & .017 & -.093 & .063 & .143 \\
\hline Autonomy (Grade 4) & $\leftrightarrow$ & Task persistence (Grade 4) & .043 & .027 & .132 & .084 & .114 \\
\hline Autonomy (Grade 4) & $\leftrightarrow$ & Skills (Grade 4) & .011 & .015 & .043 & .060 & .478 \\
\hline Task persistence (Grade 4) & $\leftrightarrow$ & Skills (Grade 4) & -.028 & .023 & -.093 & .074 & .205 \\
\hline
\end{tabular}

Note. Unstand. estimate - unstandardized coefficient, Stand. estimate - standardized coefficient, SE - standard error 